\title{
CHARGE-TRANSFER SPECTRA OF TETRAVALENT LANTHANIDE IONS IN OXIDES
}

\author{
H. E. HOEFDRAAD \\ Department of Solid State Chemistry. Physical Laboratory, University of Utrecht, Sorbonnelaan 4. Utrecht, \\ The Netherlands
}

(Received 17 November 1974)

\begin{abstract}
The charge-transfer spectra of $\mathrm{Ce}^{4+}, \mathrm{Pr}^{4+}$ and $\mathrm{Tb}^{4+}$ in a number of oxides are reported. It is noted that the position of the first charge-transfer band is fixed for the metal ion in an oxygen coordination of Vl, but varies in VIII coordination as a function of the host lattice. It is argued that this variation is inherent to the VIII coordination itself.
\end{abstract}

\section{INTRODUCTION}

IN THE past decade quite some work has been done on charge transfer (c.t.) transitions in molecular or ionic groups in which an electron is excited from a delocalized ligand molecular orbital (m.o.) to an empty or incompletely filled orbital mainly localized on the central ion of the chromophore. The position of the first c.t. band of a complex is determined by the oxidizing character of the central ion and by the properties of the set of ligands. Thus not only the reducing character of a particular ligand is of importance, but also effects due to ligand-ligand repulsion and to destabilization of the metal ion orbitals due to interaction with ligand m.o.'s[1-4].

Although most data refer to c.t. spectra of transition metal ions, c.t. transitions have also been reported for the trivalent lanthanides $\mathrm{Eu}^{3+}, \mathrm{Sm}^{3+}, \mathrm{Tm}^{3+}$ and $\mathrm{Yb}^{3+}$ in complexes with halogen ligands [5] and in oxides [6], in which the first band in the absorption spectra is ascribed to such a transition, in contrast with $\mathrm{Ce}^{3+}, \mathrm{Pr}^{3+}$ and $\mathrm{Tb}^{3+}$ where the first band is assigned to a $4 f \rightarrow 5 d$ transition, a markedly different feature being the bandwidth, which is almost twice as large for a c.t. band compared with an $f \rightarrow d$ band [7].

Since for a given element the c.t. bands shift to lower energies with increasing oxidation state, and transitions between different cationic subshells (Rydberg transitions) to higher energies, one might expect to find the c.t. bands for complexes of the tetravalent lanthanide $(\mathrm{Ln})$ ions $\mathrm{Ce}^{4+}, \mathrm{Pr}^{4+}$ and $\mathrm{Tb}^{4+}$ in an easily accessible region of the spectrum. In fact some years ago Ryan and Jørgensen [5] have reported the absorption spectra of $\mathrm{CeCl}_{6}{ }^{2-}$ and $\mathrm{CeBr}_{6}{ }^{2-}$ and Jørgensen and Rittershaus [8] described the diffuse reflection spectra of $\mathrm{Pr}^{4+}$ and $\mathrm{Tb}^{4+}$ in $\mathrm{TbO}_{2}$ and $\mathrm{Y}_{2} \mathrm{O}_{3}$ in which the broad bands in the visible region of the spectrum were ascribed to c.t. transitions. Recently the spectra of these ions in monoclinic $\mathrm{ZrO}_{2}$ have been reported [9]. It was noted that in $\mathrm{ZrO}_{2}$ and $\mathrm{Y}_{2} \mathrm{O}_{3}$ the bands of $\mathrm{Pr}^{4+}$ and $\mathrm{Tb}^{4+}$ are situated at markedly higher energies than in $\mathrm{ThO}_{2}$, a fact which cannot readily be understood.

Most complexes have been studied in solution, but in this case, since it is not possible to obtain $\mathrm{Pr}^{4+}$ and $\mathrm{Tb}^{4+}$ complexes in solution, it was necessary to work in solid samples. Solutions have the advantage that absorption spectra can be obtained, whereas solid samples can only be studied by reflection spectroscopy, because it is usually difficult to obtain single crystals. On the other hand solid samples enable a systematic study of c.t. bands in several crystal lattices, with the central metal ion in a wide range of coordinations, and with different neighbouring ions of the complex.

In order to study the tetravalent lanthanide ions it is necessary to have at one's disposal host lattices which contain tetravalent metal ions with ionic radii about equal to those of the $\mathrm{Ln}^{4+}$ ions and with their own c.t. bands far into the u.v. region. Furthermore these tetravalent ions should occur in different lattices. Thus oxidic compounds of $\mathrm{Zr}^{4+}, \mathrm{Ce}^{4+}, \mathrm{Hf}^{4+}$ and $\mathrm{Th}^{4+}$ were chosen with either the perovskite and $\mathrm{K}_{2} \mathrm{NiF}_{4}$ structure in which the tetravalent ion is coordinated octahedrally by six oxygen ions, or with the fluorite, the zircon or the scheelite structure with a tetravalent ion coordination of VIII.

One of the main difficulties with reflection spectra is to determine the band position, especially in the case of broad overlapping bands. It seemed useful, therefore, to try to resolve the broad unstructured bands, extending from the visible region up to the c.t. bands of the host lattices in the u.v., by the method of dilution in the reference white standard[10].

\section{EXPERIMENTAI}

Samples were prepared by firing intimate mixtures of high purity compounds in an oxygen atmosphere (1 atm). Starting materials were $\mathrm{BaCO}_{3}, \mathrm{SrCO}_{3}, \mathrm{ZrO}_{2}, \mathrm{HfO}_{2}, \mathrm{ThO}_{2}, \mathrm{GeO}_{2}$ and $\mathrm{SiO}_{2} \cdot \mathrm{xH}_{2} \mathrm{O} . \mathrm{ZrO}_{2}$ was prepared from $\mathrm{ZrOCl}_{2} \cdot 8 \mathrm{H}_{2} \mathrm{O}$ by recrystallization and subsequent firing as described in Ref. [11]. Rare earth oxides with nominal formula $\mathrm{CeO}_{2}, \mathrm{Pr}_{6} \mathrm{O}_{11}$ and $\mathrm{Tb}_{2} \mathrm{O}_{3}$ of 99.9 per cent purity or better were used. The rare-earth concentration in our samples varied up to 1 at. \%. Samples were checked by $\mathrm{X}$-ray analysis using a Philips diffractometer with $\mathrm{CuK} \alpha$ radiation. Diffuse reflection spectra were recorded on a Perkin-Elmer EPS/3T double-beam spectrophotometer against a $\mathrm{MgO}$ white standard. Diluted spectra were measured by diluting the sample in high-purity $\mathrm{MgO}$ until $\mathrm{R}$ varied between 90 and 100 per cent. against the same high purity $\mathrm{MgO}$ as a reference.

An attempt was made to study the behaviour of the absorption bands at lower temperatures. To that extent samples were cooled to about $130 \mathrm{~K}$ in a specially constructed sample holder by a flow of liquid nitrogen.

\section{RESULTS}

The presence of the tetravalent $\mathrm{Ln}$ ions in the host lattices used, results in the occurence of broad absorption bands in the spectra. Judging from the reflection spectra the intensity of the absorption bands is high. For $\operatorname{Pr}^{4+}$ and $\mathrm{Tb}^{4+}$ all samples with 1 per cent $\mathbf{L n}$ impurity are intensively coloured. The colours range from brightly yellow $\left(\mathrm{BaZrO}_{3}, \mathrm{ZrSiO}_{4}\right)$ through orange $\left(\mathrm{ZrGeO}_{4}\right)$ to purple and violet $\left(\mathrm{ThO}_{2}, \mathrm{ThGeO}_{4}\right)$ indicating allowed transitions. A 
Table 1. Spectral data (in $\mathrm{kK}$ ) of $\mathrm{Ln}^{4+}$ ions in VI coordination in some oxides

\begin{tabular}{|c|c|c|c|}
\hline \multirow{2}{*}{ VI coord } & \multicolumn{3}{|c|}{ o obs. (in kK) } \\
\hline & $\mathrm{Ce}$ & $\mathrm{Pr}$ & $\mathrm{Tb}$ \\
\hline $\mathrm{Sr}_{2} \mathrm{ZrO}_{4}$ & 32 & 30 & $25(s h) ; 29$ \\
\hline $\mathrm{Ba}_{2} \mathrm{ZrO}_{4}$ & 33 & $25(\mathrm{sh}) ; 29.6$ & $22(\mathrm{sh}) ; 25 ; 28.6$ \\
\hline $\mathrm{SrZrO}_{3}$ & - & $25(?) ; 30$ & $25(\mathrm{sh}) ; 29$ \\
\hline $\mathrm{BaZrO}_{3}$ & 32 & $25(?) ; 30$ & $22(s h) ; 25 ; 29.2$ \\
\hline $\mathrm{BaCeO}_{3}$ & - & $25 ; 29.6$ & 25 \\
\hline $\mathrm{BaHFO}_{3}$ & - & $25(?) ; 29.8$ & $25 ; 29$ \\
\hline BaTho $_{3}$ & 32 & $24.8 ; 29.6$ & $24 ; 29$ \\
\hline
\end{tabular}

(sh) - shoulder (?) = uncertain

Table 2. Spectral data (in $\mathrm{kK}$ ) of $\mathrm{Ln}^{4+}$ ions in VIII coordination in some oxides

\begin{tabular}{llll}
\hline & \multicolumn{4}{c}{ Oobs.in $\mathrm{kk}$} \\
& $\mathrm{Pr}$ & $\mathrm{Tb}$ \\
\hline $\mathrm{ZrSiO}_{4}$ & 31.5 & $22.7 ; 23.8 ; 29.824 ; 29$ \\
$\mathrm{ZrGeO}_{4}$ & 31,5 & 21,$8 ; 23 ; 29$ & $21.8 ; 23 ; 29$ \\
$\mathrm{ThGeO}_{4}$ & 31 & $18.4 ; 22 ; 30$ & - \\
$\mathrm{ThO}_{2}$ & - & $19 ; 22.4 ; 29$ & $20 ; 23 ; 30.4$
\end{tabular}

summary is given in Tables 1 and 2. All data were derived from spectra of samples diluted in $\mathrm{MgO}$.

The compounds $\mathrm{Ba}_{2} \mathrm{ZrO}_{4}$ and $\mathrm{Sr}_{2} \mathrm{ZrO}_{4}$ have the $\mathrm{K}_{2} \mathrm{NiF}_{4}$ structure with $\mathrm{Zr}$ in an octahedral oxygen coordiantion. The compounds $\mathrm{AMO}_{3}(\mathrm{M}=\mathrm{Zr}, \mathrm{Ce}, \mathrm{Hf}$, Th) have the perovskite structure with the same coordination for $\mathrm{M}$. Most spectra of $\operatorname{Pr}^{4+}$ and $\mathrm{Tb}^{4+}$ in these host lattices show a band with two distinct maxima at more or less fixed positions (Table 1, Fig. 1). No changes were detected at

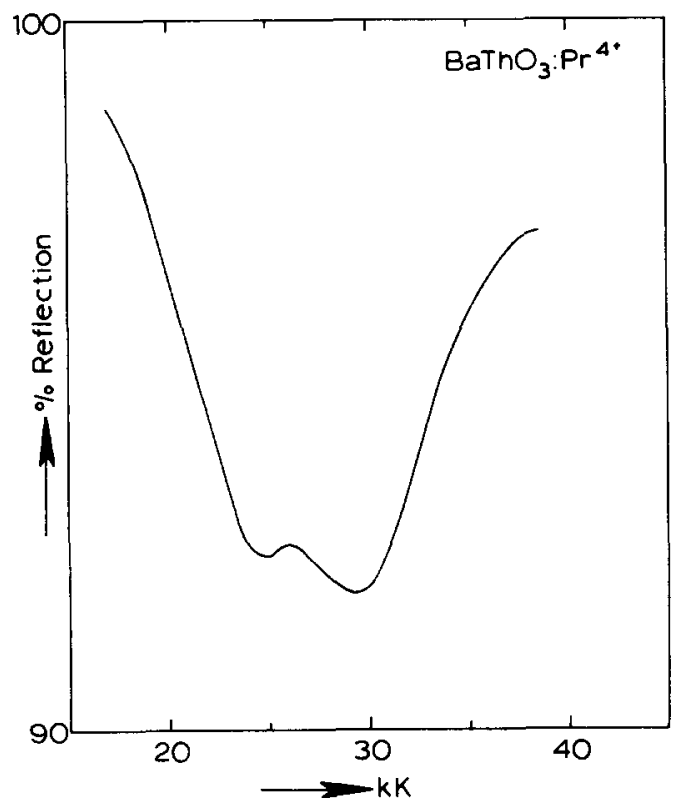

Fig. 1. Reflection spectrum of $\mathrm{BaThO}_{3}: \mathrm{Pr}^{4+}(298 \mathrm{~K})$. lower temperatures. Notable exceptions are $\mathrm{BaZrO}_{2}: \mathrm{Tb}^{4+}$ and $\mathrm{Ba}_{2} \mathrm{ZrO}_{4}: \mathrm{Tb}^{4+}$ where an extra shoulder is found at $22 \mathrm{kK}$ which does show some temperature dependence (Fig. 2). In the case of $\mathrm{Ce}$ the band is found at higher energies. A second band could not be observed, mainly due to the appearance of the c.t. bands of the host lattices.

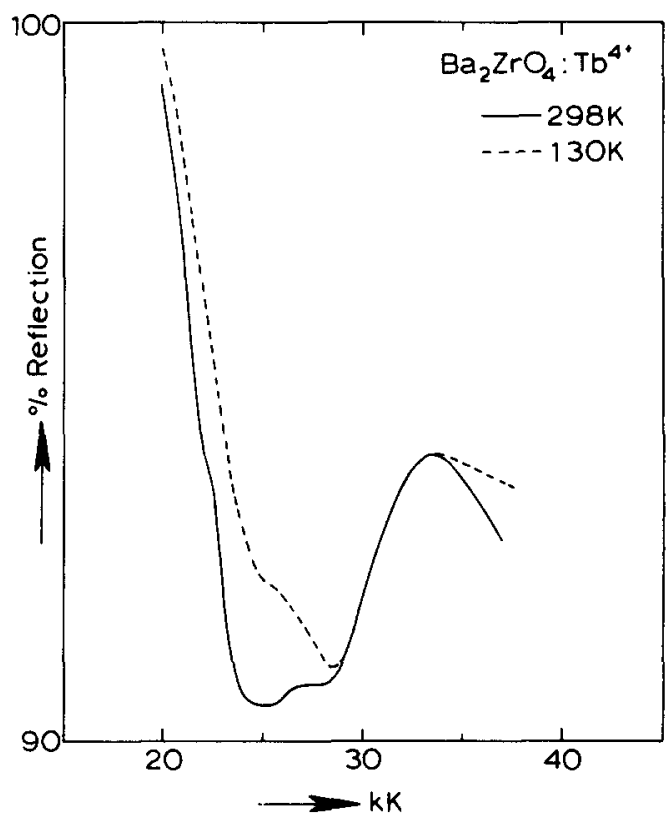

Fig. 2. Reflection spectrum of $\mathrm{Ba}_{2} \mathrm{ZrO}_{4}: \mathrm{Tb}^{4+}$

$\mathrm{ThO}_{2}$ has the fluorite structure, $\mathrm{ZrSiO}_{4}$ and $\mathrm{ThGeO}_{4}$ have the zircon structure and $\mathrm{ZrGeO}_{4}$ has the scheelite structure. In these compounds $\mathrm{Zr}$ and $\mathrm{Th}$ are surrounded by eight oxygen ions. For $\mathrm{Pr}^{4+}$ and $\mathrm{Tb}^{4+}$ two absorption bands can be distinguished of which the one at lower energy clearly has two maxima (Figs. 3 and 4). The lower maximum appears to shift as a function of the host lattice.

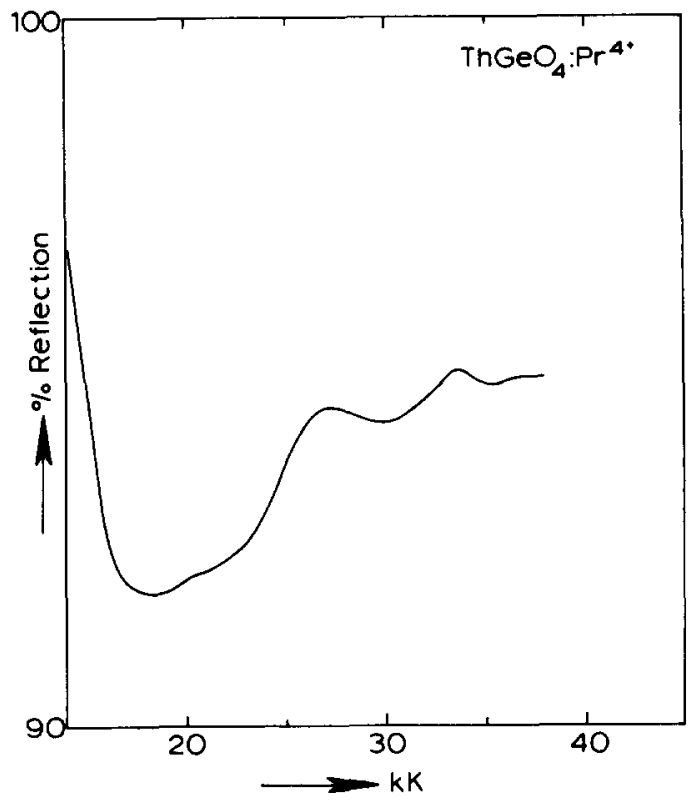

Fig. 3. Reflection spectrum of $\mathrm{ThGeO}_{4}: \mathrm{Pr}^{4+}$ (zircon structure) (298 K). 


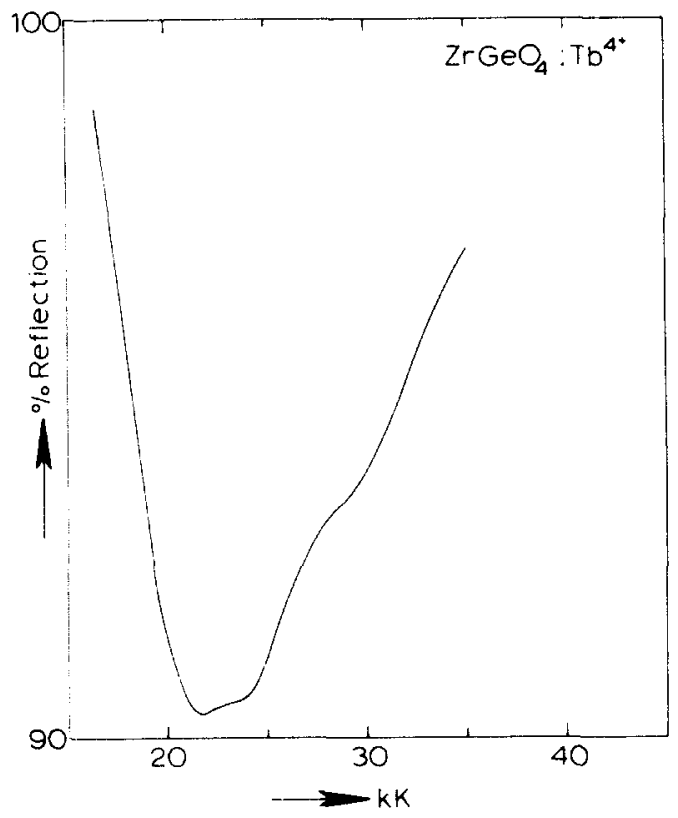

Fig. 4. Reflection spectrum of $\mathrm{ZrGeO}_{4}: \mathrm{Tb}^{4+}(298 \mathrm{~K})$.

For $\mathrm{Ce}^{4+}$ the position of the first band does not change (Table 2).

Under our experimental conditions it is not always possible to incorporate the Ln-ions in the tetravalent state in the desired host lattices. It turned out that their valency was three in part of the lattices used. Even in those cases in which incorporation was achieved, it sometimes was hard to perform. This implies that part of the lanthanide dopant may still be in the lower oxidation state, and necessitates to consider the possibility of transitions between the oxidation states Ln(III, IV). Jørgensen and Rittershaus [8], however, have given arguments which make an assignment of the bands to this type of transition improbable. Furthermore it is often possible to identify the $f \rightarrow f$ transitions of trivalent $\mathrm{Pr}$ in a reflection spectrum even at very low concentrations $(0.1$ at. \%). In cases where incorporation of the tetravalent ions proved to be easy no trace of these bands could be found. In some cases, however, the $f \rightarrow f$ transitions of the trivalent ion were superimposed upon the broad absorption bands due to the tetravalent ion.

Cerium poses another problem because trivalent cerium is known to have its $f \rightarrow d$ absorption bands in the region around $30 \mathrm{kK}$. This is also the region where the absorption bands of the $\mathrm{Ce}^{4+}$ complex may occur. In the case of $\mathrm{Ce}^{4+}$. therefore, only data are reported for compounds where incorporation of $\mathrm{Pr}^{4+}$ and $\mathrm{Tb}^{4+}$ presented no problems.

In not a single instance luminescence from the tetravalent $\mathrm{Ln}$ ions could be detected for excitation with u.v. radiation, not even at $5 \mathrm{~K}$.

\section{DISCUSSION}

Since the possibility that the bands can be attributed to mixed oxidation states Ln(III, IV) has already been excluded, two alternative assignments to the absorption band(s) of the $\mathrm{Ln}^{4+}$ ions remain, viz. $4 f \rightarrow 5 d$ transitions or c.t. transitions from one of the delocalized ligand m.o.'s to a m.o. mainly localized on the metal ion. In $\mathrm{Ce}^{3+}$ the $4 f \rightarrow 5 d$ transitions occur at about $30 \mathrm{kK}[5,12]$ and in $\operatorname{Pr}^{3+}$ and $\mathrm{Tb}^{3+}$ at even higher wavenumbers, so that for the tetravalent ions these transitions are expected at much higher energies. This leaves only the latter assignment, i.e. c.t. transitions as proposed already in Ref. [8].

The spectra of the $\mathrm{Ln}^{4+}$ ions in VI and VIII coordination will be considered separately. Afterwards some general conclusions will be drawn.

\section{(a) The VI coordination}

The $\mathrm{Ln}^{4+}$ ions are expected to be incorporated into the host lattices at the sites of the tetravalent metal ions on the basis of the ionic radii. The existence of $\mathrm{BaCeO}_{3}$, $\mathrm{BaPrO}_{3}$ and $\mathrm{BaTbO}_{3}$ indicates that such an incorporation should present no problems.

The symmetry at the site of the tetravalent metal ion is $O_{h}$ in the perovskite structure and $D_{4 h}$ in the $\mathrm{K}_{2} \mathrm{NiF}_{4}$ structure. The similarity of the spectra of the $\mathrm{Ln}^{4+}$ ion in both structures indicates, however, that $O_{h}$ is a good approximation in the latter case.

If we follow Schmidtke's topological treatment of an octahedron of six ligands[13], the sequence of ligand m.o.'s is,

$$
a_{1 \mu}<1 t_{1 u}<t_{2 k}<t_{2 u}<t_{12}=e_{k}<2 t_{1 u}
$$

These ligand m.o.'s are not yet perturbed by the metal ion orbitals. This implies that the ligand $e_{g}$-orbitals are expected to be stabilized considerably on interaction with the $d$-levels of the central ion with $e_{\mathrm{g}}$ symmetry in $O_{n}$. Thus, undoubtedly, the first allowed c.t. band is the transition $t_{k,} \rightarrow f$, because the transition $2 t_{1 \prime \prime} \rightarrow f$ is partly forbidden. In fact we ascribe the first absorption band in the case of $\mathrm{Pr}^{4+}$ and $\mathrm{Tb}^{4+}$ and the band of $\mathrm{Ce}^{4+}$ to this transition. The designation $f$, refers to the lowest excited c.t. state of the central ion. The assignment of the second peak of the absorption band of $\mathrm{Pr}^{4+}$ and $\mathrm{Tb}^{4+}$ is more difficult. These central ions have several excited states within their $f^{n}$ configuration a few $\mathrm{kK}$ above the lowest and, in addition, an overlap with a next band arising from the transition $t_{2 k} \rightarrow f$ can be expected.

Within the experimental error there is no influence of the host lattice on the absorption maxima, neither in going from $\mathrm{BaZrO}_{3}$ to $\mathrm{SrZrO}_{3}$ nor in going from $\mathrm{BaZrO}_{3}$ to $\mathrm{Ba}_{2} \mathrm{ZrO}_{4}$ nor in the sequence $\mathrm{BaMO}_{3}(\mathrm{M}=\mathrm{Zr}, \mathrm{Ce}, \mathrm{Hf}, \mathrm{Th})$. This excludes the possibility of a considerable destabilization of the metal ion $f$ orbitals, as well as a considerable increase of ligand-ligand repulsion if the $\mathrm{Ln}-\mathrm{O}$ bond becomes shorter, a matter to which we will refer later on.

The nature of the shoulder at $22 \mathrm{kK}$ in $\mathrm{BaZrO}_{3}-\mathrm{Tb}^{4+}$ and $\mathrm{Ba}_{2} \mathrm{ZrO}_{4^{-}} \mathrm{Tb}^{4+}$ is not completely understood, especially since this shoulder seems to behave completely different from the remainder of the band upon cooling. We have the impression that the intensity of the shoulder decreases upon cooling. This could indicate the possibility of a parity-forbidden transition, which has become partially allowed through vibronic coupling. Further investigation will, however, be necessary to clarify this problem.

\section{(b) The VIII coordination}

The site symmetry of the impurity $\mathrm{Ln}^{4+}$ ion in the fiuorite structure is $O_{h}$, in the zircon structure $D_{2 d}$ and in the scheelite structure $S_{4}$. The similarity of the spectra of the $\mathrm{Ln}^{4+}$ ions in $\mathrm{ThO}_{2}$ and $\mathrm{ThGeO}_{4}$ is so strong that it seems reasonable to treat all sites as having $O_{h}$ symmetry and to consider the non-cubic crystal field components as small perturbations.

It is evident that the shift of the first absorption band as a function of the host lattice cannot be explained by a destabilization of the orbitals mainly localized on the 
metal ion by mixing with a ligand m.o. with the same symmetry designation. The $f$-orbitals are usually considered to be mainly non-bonding and there is no reason to believe this assumption to be incorrect. If such an effect would occur at all it is expected to be much smaller than in the $d$ metal complexes. An indication that this is correct follows from the spectra of the $\mathrm{Ln}^{4+}$ ions in octahedral coordination, where the absence of an appreciable shift excludes this possibility as well as the possibility of strong ligand-ligand repulsion (see above).

The positions of the c.t. bands of a $\mathrm{Ln}^{4+}$ ion complex in silicates and germanates may be different from those in "pure" oxides, because the $\mathrm{Si}-\mathrm{O}(\mathrm{Ge}-\mathrm{O})$ bond is strongly covalent. The first bands in $\mathrm{ThO}_{2}$ and $\mathrm{ThGeO}_{4}$, however, are located at roughly the same position. This does imply that such an effect cannot be the major factor in explaining the shift.

It is noteworthy that in those compounds where the largest $\mathrm{Ln}-\mathrm{O}$ distance can be expected $\left(\mathrm{ThO}_{2}, \mathrm{ThGeO}_{4}\right)$ the first maximum is located at the lowest energy. This tendency is directly contradictory to an explanation based on strong ligand-ligand repulsion.

These arguments lead to the conclusion that the shift is inherent to the VIII coordination itself, and thus we again consider the sequence of ligand m.o.'s using the topological treatment described by Schmidtke. Considering only nearest neighbour interaction, we found for the orbital sequence in a cubic chromophore with $O_{h}$ symmetry,

$$
a_{1 g}=e_{g}<1 t_{1 u}=t_{2 u}<1 t_{2 g}<2 t_{1 u}<t_{1 g}=2 t_{2 g}<e_{u}=a_{2 u} .
$$

Again this is the sequence of ligand m.o.'s unperturbed by metal ion orbitals. We note that there are two ligand m.o.'s of $t_{2 g}$ symmetry. A comparable situation exists in the case of a $d$-metal ion in an octahedral surroundings with two ligand m.o.'s of $t_{1 u}$ symmetry. In this case the first c.t. band in the absorption spectrum must be attributed to the transition $2 t_{1 u} \rightarrow d$ and not to $t_{2 u} \rightarrow d$ [4]. This can partially be explained by a mixing of the two ligand m.o.'s resulting in a destabilization of the highest $t_{1 u}$ ligand m.o. (see 1)[13]. But in the case of a cube, still not considering interactions of the ligand m.o.'s with the central ion orbitals, the two sets of ligand $t_{2 g}$ orbitals do not mix. This is caused by the fact that we cannot distinguish between the two different sets of ligand atomic orbitals as in octahedral coordination, where one set is used in constructing the ligand $\sigma$ m.o.'s and the other in constructing the ligand $\pi$ m.o.'s[15].

We now consider the perturbation caused by the central ion orbitals. The important feature is the mixing of the metal ion $t_{2 g}$ orbitals from the $5 d$-level with both ligand m.o.'s. This mixing destroys their mutual orthogonality, resulting in a rearrangement. As a consequence the position of the highest ligand $t_{2 g}$ m.o.'s relative to the $t_{1 g}$ ligand m.o.'s depends strongly on the energetic position and the extent of delocalization of the $d$-orbitals of the $\mathrm{Ln}^{4+}$ ion. This in fact should be the most important factor in explaining the shift of the first c.t. band of the $\mathrm{Ln}^{4+}$ ions in VIII coordination.

On the bases of arguments given above the first maximum in VIII coordination for $\mathrm{Pr}^{4+}$ and $\mathrm{Tb}^{4+}$ should be ascribed to the transition $2 t_{2 g} \rightarrow f$ and the maximum at about $22.5 \mathrm{kK}$ to $t_{18} \rightarrow f$, although in $\mathrm{ZrSiO}_{4}$ the order could very well be reversed. The band at about $29 \mathrm{kK}$ poses the same problem as the second maximum for VI coordination.
For $\mathrm{Ce}^{4+}$ the situation is markedly different. The band does not shift and is situated at more or less the same position as in VI coordination. The fact that $\mathrm{Ce}^{4+}$ has an $f^{\circ}$ configuration, makes it difficult to predict the behaviour of the $5 d$ orbitals. Further analysis will be necessary to understand this behaviour completely.

\section{(c) Optical electronegativity}

If we ascribe the first maximum at about $24.5 \mathrm{kK}$ in the absorption spectra of $\mathrm{Pr}^{4+}$ and $\mathrm{Tb}^{4+}$ in VI coordination to the transition $t_{1 g} \rightarrow f$, and if we accept for the optical electronegativity of oxygen $\chi_{\text {opt }}\left(\mathrm{O}^{2-}\right)=3 \cdot 2[9]$, we arrive at a value of $\chi_{\text {uncorr }}=2.4$ for both $\mathrm{Pr}^{4+}$ and $\mathrm{Tb}^{4+}$. We have used Jørgensens definition [15] of the uncorrected optical electronegativity.

$$
\sigma=\left[\chi_{\text {opt }}(\mathrm{X})-\chi_{\text {uncorr }}(\mathrm{M})\right] \times 30 \mathrm{kK}
$$

where $\sigma$ is the position of the c.t. band, $\chi_{\mathrm{opt}}(\mathrm{X})$ the optical electronegativity of the anion and $\chi_{\text {uncorr }}(M)$ the uncorrected optical electronegativity. This is slightly lower than values calculated from III-IV oxidation potentials in chromophores with halogen ligands [16]. For $\mathrm{Ce}^{4+}$ we get $\chi_{\text {uncorr }}=2 \cdot 1$ if we take $33 \mathrm{kK}$ for the position of the first band, in excellent agreement with the values reported in Ref. [8].

It will be evident that a calculation of $\chi$ uncorr of $\mathrm{Pr}^{4+}$ and $\mathrm{Tb}^{4+}$ from the position of the first band for VIII coordination would be meaningless, since this optical electronegativity would not be a property characteristic of a particular ion because it would also characterise a specific surroundings.

If we calculate $\chi$ uncorr from the transition $t_{1 g} \rightarrow f$ we get values which are consistent with the values obtained for VI coordination; for $\mathrm{Pr}^{4+}$ and $\mathrm{Tb}^{4+} \chi$ uncorr $=2.45$ and for $\mathrm{Ce}^{4+} \chi_{\text {uncorr }}=2 \cdot 15$.

This procedure limits of course the practical value of the optical electronegativity in predicting the approximate position of the first c.t. band of an ion in VIII coordination. This, however, is a minor limitation compared with a situation where the value would be different in each compound.

\section{(d) The $\mathrm{Eu}^{3+}$ ion}

It should be noted that an unexpected variation of the position of the first c.t. band has also been noted for $\mathrm{Eu}^{3+}[6]$. Closer analysis reveals that here again the position of the band is more or less fixed in VI coordination and that the strong variation occurs for VIII coordination, so that the same line of reasoning probably applies here too. Elsewhere we will discuss the $\mathrm{Eu}^{3+}$ ion further[17].

\section{(e) Luminescence}

It is well known that highly-charged cations like $\mathrm{Nb}^{5+}$, $\mathrm{W}^{6+}$ and $\mathrm{U}^{6+}$ often display luminescence[18-20], which can be attributed to transitions between metal ion orbitals and ligand m.o.'s. The $\mathrm{Eu}^{3+}$ ion on the other hand displays a red luminescence which can be attributed to transitions within the $f^{6}$ configuration. We note that the tetravalent Ln ions display no luminescence at all. It is hardly conceivable that the energy could be lost by radiationless processes without another intermediary excited state. It is unlikely that this intermediary is one of the higher excited $f$-states of the central ion, so that one is led to conclude that either an excited $d$-state or a state which arises from a hole in another ligand m.o. must play a part in the process. 
Acknowledgements - The author is much indebted to Prof. Dr. G. Blasse for encouraging this work and for many stimulating discussions. Mr. F. M. A. Stegers is gratefully acknowledged for the preparation of and spectral measurements on the samples.

\section{REFERENCES}

1. C. K. Jørgensen and W. Preetz, Z. Naturforsch. 22a, 945(1967).

2. C. K. Jørgensen, Modern Aspects of Ligand Field Theory. North Holland, Amsterdam (1971).

3. H. H. Schmidtke, Coord. Chem. Rev. 2,3 (1967).

4. C. K. Jørgensen, Progr. Inorg. Chem. 12, 101 (1970).

5. J. L. Ryan and C. K. Jørgensen, J. Phys. Chem. 70, 2845 (1966).

6. G. Blasse, J. Solid State Chem. 4, 52 (1972); and references therein.

7. J. L. Nugent, R. D. Baybarz, J. L. Burnet and J. L. Ryan, J. Phws. Chem. 77, 1528 (1973).

8. C. K. Jørgensen and E. Rittershaus, Mat. Fys. Medd. Dan. Vid. Selskab 35, no. 15 (1967)
9. N. van Vugt, T. Wigmans and G. Blasse. J. Inorg. Nucl. Chem. 35. 2602 (1973).

10. G. Kortüm, Reflectance Spectroscopy. Springer, Berlin (1969)

11. J. F. Sarver, I. Electrochem. Soc. 113, 124 (1966).

12. C. K. Jørgensen, Mol. Phys. 5, 271 (1962).

13. H. H. Schmidtke, J. Chem. Phys. 45, 3920 (1966).

14. G. N. Henning, A. J. McCaffery, P. N. Schatz and P. J. Stephens, J. Chem. Phys. 48, 5656 (1968)

15. C. K. Jørgensen, Absorption Spectra and Chemical Bonding Pergamon Press, New York (1962).

16. L. J. Nugent, R. D. Baybarz, J. L. Barnett and J. L. Ryan, I Inorg. Nucl. Chem. 33, 2503 (197)

17. H. E. Hoefdraad. Thesis. University of Utrecht, to be published.

18. G. Blasse and A. Bril. Z. Phys. Chem. N.F. 57. 187 (1968).

19. F. A. Kröger. Some Aspects of Luminescence of Solids, Elsevier, Amsterdam (1948).

20. J. Th. W. de Hair and G. Blasse. J. Luminescence 8.97 (1973). 